\title{
Trayectorias familiares y experiencias individuales: el caso de los esclavizados de los Diez de Andino en Santa Fe (1763-1822) ${ }^{1}$
}

\author{
Family trajectories and individual experiences: the case of the \\ enslaved of the Diez de Andino in Santa Fe (1763-1822)
}

\author{
Gonzalo Cáceres \\ Facultad de Humanidades y Ciencias, \\ Universidad Nacional del Litoral (Argentina) \\ caceresgonza@hotmail.com
}

\begin{abstract}
Resumen
Este artículo reconstruye las trayectorias familiares y las experiencias individuales de un grupo de esclavizados que pertenecieron a una de las familias principales de Santa Fe: los Diez de Andino. En primer lugar, se reseñan los roles de los esclavos en la producción y en el servicio doméstico y se analizan sus uniones matrimoniales como parte de una política de arraigamiento y control de la mano de obra ejercida por los amos. En segundo lugar, se ofrece un panorama de las enfermedades, dolencias y causas de muerte de los cautivos, se analizan sus estrategias de resistencias y adaptación a la esclavitud y, finalmente, se desarrollan las historias de tres grandes familias esclavas que, generación tras generación, estuvieron ligadas a ese importante linaje santafesino. La fuente principal en la que se basa este estudio es un manuscrito redactado por Don Manuel Ignacio, uno de los últimos cabeza de familia de los Diez de Andino, en articulación con diversos fondos documentales (censales, eclesiásticos, notariales, capitulares).
\end{abstract}

\section{Palabras Clave}

Santa Fe; Esclavitud; Resistencia; Adaptación; Familias esclavas.

\begin{abstract}
This article reconstructs the family trajectories and individual experiences of a group of enslaved persons properties of one of the main families of Santa Fe (Argentina): the Diez de Andino. Firstly, I trace slave's roles in production and domestic service. Then I analyze marital unions as part of a slaveholder's policy of rooting and controlling slaves. Secondly,
\end{abstract}

\footnotetext{
${ }^{1}$ Esta investigación se enmarca dentro del PICT 2017-3306 “Esclavitud, emancipación y ciudadanía en el Río de la Plata. Estudios comparados de africanos y afrodescendientes en Buenos Aires, el Litoral, Cuyo y Córdoba". Instituto de Historia Argentina y Americana "Dr. Emilio Ravignani", CONICET- UBA y Agencia Nacional de Promoción Científica y Tecnológica, dirigido por Magdalena Candioti.
}

Esta obra está sujeta a la Licencia Reconocimiento-NoComercial-CompartirIgual 4.0 Internacional de Creative Commons. http://creativecommons.org/licenses/by-nc-sa/4.0/ 


\section{Gonzalo Cáceres}

an overview of the captive's diseases, ailments and causes of death is offered, and their strategies of resistance and adaptation are analyzed. Finally I trace, the stories of three large enslaved families that generation after generation were linked to one of the Santa Fe' more important lineage. The main source on which this study is based on is a manuscript written by Don Manuel Ignacio, one of the last head of the family of the Andino, in articulation with various documentary collections (census, ecclesiastical, notarial, capitular).

\section{Keywords}

Santa Fe; Slavery; Resistance; Adaptation; Slave families.

\section{Introducción}

El 27 de noviembre de 1816 Manuel Ignacio Diez de Andino, miembro de una de las familias principales de Santa $\mathrm{Fe}^{2}$, comenzó a redactar un manuscrito en cuyas primeras líneas puede leerse:

“apunte de los esclavos que quedaron el 27 del mes de abril de 1763 a que falleció mi señor padre Don Bartolomé Diez de Andino, y los que después de esta fecha, han nacido, y los que he comprado y sus destinos"3.

Con esas palabras se inicia un documento que consta de 9 fojas en las que el autor se ocupó de asentar con cuidadoso detalle información importante sobre su plantel de esclavos. En dicho manuscrito, Manuel Ignacio registró datos sobre el perfil de estas personas, como el nombre, la edad, el sexo, el oficio y la "calidad". Además consignó referencias precisas sobre la constitución de grupos familiares registrando casamientos, bautismos y defunciones y hasta anotó datos sensibles sobre las enfermedades, dolencias y causas de muerte de estos hombres, mujeres y niños que por generaciones estuvieron bajo su propiedad y la de su padre. Finalmente, registró las donaciones, compras y ventas de esclavos que fue haciendo en distintos momentos.

Es preciso señalar que este documento, que hasta el momento no ha sido estudiado, forma parte de un conjunto de escritos redactados por el mismo Manuel Ignacio que incluyen inventarios de tierras, ganados y otras propiedades, registros de actividades comerciales, poderes notariados, intercambios epistolares, entre otros, que se conservan en la colección de documentos de su familia en el Archivo General

\footnotetext{
2 La historia de la familia Diez de Andino, la centralidad que tuvieron algunos de sus integrantes en la economía regional durante la etapa colonial y posrevolucionaria, sus redes comerciales y sus prácticas empresariales han sido objeto de importantes estudios. Al respecto véase Tarragó (1993, 1994,1996, 2004, 2010), Barriera \& Tarragó (2003, 2005, 2006a), Caula \& Tarragó (2003). En este trabajo, sin embargo, nuestro eje estará puesto en el análisis de las trayectorias de las personas esclavizadas que estuvieron bajo el dominio de Bartolomé primero, y tras su fallecimiento, de su hijo y único heredero, Manuel Ignacio.

${ }^{3}$ Archivo General de la Provincia de Santa Fe (AGPSF), Colección Diez de Andino (CDA), Legajo 62, Carpeta 1, Manuel Ignacio Diez de Andino. Registro de esclavos, 27 de noviembre de 1816, fojas 1-9.
} 


\section{Trayectorias familiares y experiencias individuales: el caso de los esclavizados de los Diez de Andino en Santa Fe (1763-1822)}

de la Provincia de Santa Fe, algunos de los cuales han sido analizados en Tarragó (1993, 1996, 2004) y en Caula \& Tarragó (2003). Además de este tipo de escritos, Manuel Ignacio fue el responsable de la redacción de un "diario", en el que a manera de crónica, relató día a día los sucesos políticos más importantes por los que atravesó Santa Fe durante el período 1815-1822, entre los que destacan la consagración de la autonomía provincial con el nombramiento de Francisco Antonio Candioti como gobernador interino en 1815 por el Cabildo santafesino bajo la protección de la Liga de los "Pueblos Libres", las invasión porteña con las expediciones de Juan José Viamonte y Eustaquio Díaz Vélez en 1816 -que provocaron importantes pérdidas materiales y humanas para la ciudad- y las campañas militares de Estanislao López desde1818 hasta 1821(Diez de Andino, 2008; Donghi, 2002 [1972]; Barriera \& Tarragó, 2006b).

En cuanto a su estructura, la fuente presenta cierto orden y hay evidencias -como algunas anotaciones cuyas fechas llegan hasta los últimos días de vida de Manuel Ignacio, en 1822- de que la misma fue construyéndose en diferentes tramos. En la foja 2 el autor realizó un inventario de los esclavos que quedaron de la herencia de su padre. Desde la foja 3 a la 5 detalló información de una gran familia -quizás la más grande- de esclavizados que empezó a formarse desde los tiempos en que vivía Don Bartolomé: la de Juana y Juan. En la foja 6 consignó los datos de otra importante familia que estuvo bajo su dominio y el de su padre: la de Catalina y Antonio. En la foja 7 registró información individual sobre otros esclavos que ingresaron a su patrimonio por distintas vías, como la compra, el cobro de deudas o a través de la dote de su esposa, Doña Josefa Terán. Finalmente, en las fojas 8 y 9, consignó datos sobre esclavizados comprados en "pública almoneda de cuenta de temporalidades pertenecientes a los bienes de los jesuitas"4, entre los que figura otra importante familia de esclavos: la de Teresa e Hipólito Cabrera.

Este trabajo trata sobre las historias de vida de esos esclavizados. Utilizaremos la información consignada en el manuscrito para, en un primero momento, ofrecer un panorama de los roles que los esclavos cumplieron en las distintas propiedades de los Andino; de las enfermedades, traumas y dolencias por ellos padecidas; y de las uniones matrimoniales que se efectuaron entre esclavizados y entre éstos con personas libres. Luego, a través de la articulación de diversos fondos documentales (como los registros parroquiales ${ }^{5}$, el censo de población levantado en la ciudad entre 1816-176, los protocolos notariales y las actas capitulares) nos concentraremos en

\footnotetext{
4 Sobre los bienes de la compañía de Jesús en Santa Fe al momento del extrañamiento ver las importantes contribuciones realizadas por Calvo (1993), Areces, (2004) y Troisi Melean (2012).

5 En Santa Fe colonial, hasta 1787, el registro de los sacramentos (bautismos, matrimonios, defunciones, etc.) se realizó de manera segregada, a partir del establecimiento de dos curatos: el de "españoles" y el de "naturales". La parroquia de San Roque fue la encargada de brindar asistencia espiritual a negros, mulatos, pardos, chinos, mestizos e indios y de dejar constancia de hitos vitales en las trayectorias de estas personas. Por ello, la consulta de este repositorio documental es verdaderamente importante a los fines de nuestro trabajo. Un estudio exhaustivo de la historia del curato de naturales en Santa Fe en Moriconi (2011).

${ }^{6}$ AGPSF, Padrón de población de la ciudad de Santa Fe de 1816-17, Tomo 1, Legajo 1 y 8, Fs. 170-210. Sección Gobierno.
} 


\section{Gonzalo Cáceres}

reconstruir las trayectorias de las tres familias esclavas antes mencionadas, enfocándonos en sus experiencias cotidianas y en sus interacciones y formas de vinculación con sus amos y con los demás actores sociales. En ese camino intentaremos dar cuenta de cómo y dónde vivían, en qué actividades fueron empleados o se desempeñaron, cuáles fueron sus padecimientos y qué estrategias de resistencia y adaptación desarrollaron, cómo transcurrieron sus vidas familiares, con quiénes "eligieron" casarse o fueron casados, qué posibilidades de movilidad social tuvieron. Con ello buscamos echar luz sobre la capacidad de agencia y la creatividad de los cautivos para forjar sus propios destinos (Mallo, 2005).

En las últimas décadas la historiografía sobre africanos en el Rio de la Plata ha conocido un notable impulso. Diferentes historiadores se han enfocado en una variedad de temas tales como sus prácticas asociativas y religiosas (Rosal, 2009), su participación armada en las gestas independentistas (Mallo \& Telesca, 2010; Guzmán, 2013), sus posibilidades de inserción en el mercado laboral como artesanos (Johnson, 2013), su acceso a la justicia para reclamar derechos (Candioti, 2010; Rebagliati, 2014a), el estudio de los lazos de amistad, solidaridad y camaradería emergentes de la trata Atlántica y de su participación en los ejércitos de la revolución (Borucki, 2017), entre otros.

En Santa Fe, el estudio de la esclavitud ha ocupado un lugar marginal en la agenda de investigaciones la historiografía clásica. Obras imponentes como "Historia de la ciudad y provincia de Santa Fe" de Manuel Cervera (1907) apenas registran la presencia de los africanos y sus descendientes sin detenerse a reflexionar sobre ellos. Las primeras producciones sistemáticas sobre esclavizados las produjeron Agustín Zapata Gollán (1987) y Catalina Pistone (1996). Aunque pioneras, ambas investigaciones enfatizaron sobre el supuesto trato benévolo que las elites propiciaban a sus esclavos, obturando la posibilidad de pensar en las relaciones conflictivas existentes entre estos actores. Según estas visiones, la "familiaridad" hacia los esclavizados era tal que éstos la retribuían con un "buen comportamiento, sumisión y cariño" (Pistone, 1996: 24). Es preciso señalar que estas explicaciones estuvieron ligadas a la imagen "benigna" de la esclavitud colonial que construyeron las grandes narrativas nacionales inspiradas en los relatos de viajeros que visitaron el Río de la Plata en aquella época, pero también que son el resultado de una lectura sesgada y poco profunda de las fuentes históricas (Rebagliati, 2014b). Luego de estas producciones, quien se ocupó del estudio de las personas esclavizadas en Santa Fe -poniendo en cuestión esa supuesta benignidad- fue María del Rosario Baravalle (2001, 2006, 2018), cuyas investigaciones -recientemente re-editadas- se orientaron a dar cuenta de las modalidades del tráfico y a describir a la población cautiva, ofreciendo información sobre volúmenes, precios y actividades en las que fueron ocupados. Actualmente la presencia negra durante la primera mitad del siglo XIX viene siendo sistemáticamente abordada por Magdalena Candioti (2016a, 2018). Esta historiadora, a diferencia de sus antecesores, se ha enfocado con mayor profundidad en las acciones, resistencias y estrategias cotidianas de los esclavizados para lograr objetivos tan preciados como la libertad, enfatizando en la complejidad 


\section{Trayectorias familiares y experiencias individuales: el caso de los esclavizados de los Diez de Andino en Santa Fe (1763-1822)}

y en el carácter negociado de las relaciones entre amos y esclavos. Por último, algunos trabajos centrados exclusivamente sobre el siglo XVIII han comenzado a saldar la importante vacancia de estudios que sobre la problemática esclavista existía para dicho período, analizando al mercado, las rutas esclavistas hacia la ciudad, las uniones matrimoniales, y algunas prácticas de resistencia como las fugas (Silvestri, 2017, 2019; Moriconi, 2018; Cáceres, 2019a, b). Esta propuesta pretende ser una contribución más en ese sentido y analiza un tema que aún no ha sido explorado, como lo son las trayectorias individuales y familiares de un conjunto de esclavos que pertenecieron a una de las familias que mayor gravitación tuvo en la ciudad a lo largo del siglo XVIII.

\section{Los esclavos de los Andino: de Bartolomé a Manuel Ignacio}

A su muerte, acaecida en 1763, Don Bartolomé Diez de Andino dejó por testamento 26 esclavos $^{7}$, un número considerable que lo ubicaba entre los mayores propietarios de esclavizados para la época, sólo equiparable a los poseídos por otros importantes vecinos de la elite, como Don Manuel Maciel ${ }^{8}$, Don José Fernández Villamea ${ }^{9}$ y Don Francisco Antonio de Vera Mujica ${ }^{10}$, quienes en sus testamentos declararon poseer 20, 18 y 21 esclavos respectivamente. En Santa Fe, para la misma época, sólo la Compañía de Jesús llegó a tener más esclavos que estos particulares, superando el centenar (Calvo, 1993; Areces, 2004; Troisi Melean, 2012).

Como Manuel Ignacio era su único heredero, todos estos esclavos pasaron a sus manos. Según se aprecia en el manuscrito redactado por Manuel, con el pasar del tiempo se produjeron algunas compras, nacimientos, decesos y donaciones que hicieron que este plantel se fuera renovando. Por estas fluctuaciones, se nos hace difícil tener certezas del número exacto de esclavos que tuvo la familia Andino después del fallecimiento de Bartolomé. Si bien en el censo de población levantado en la ciudad entre 1816-17 fueron registrados en casa de Manuel Ignacio 15 esclavos y otros 4 en casa de una de sus hijas, Ramona Andino (Candioti et. al., 2019: 557), creemos que estos números no constituyen la totalidad de sus esclavos dado que en dicho censo no se contemplaron los que habitaban las propiedades rurales de esta familia ${ }^{11}$.

\footnotetext{
7 Departamento de Estudios Etnográficos y Coloniales (DEEC), Escrituras Públicas (EP), Tomo 16, 1763, Fojas 94-111. El salto es significativo si lo comparamos con los apenas 5 esclavos que dejó a su muerte su padre, Don Miguel Diez de Andino (Tarragó, 1993: 53). Por otro lado, de todos los esclavos que figuran en el testamento de Bartolomé, sólo 2 -Juan "correntino" y Pascuala- no aparecen registrados en el manuscrito que Manuel Ignacio comenzó a redactar en 1816.

${ }^{8}$ DEEC, EP, T. 16, 1765, Fs. 290-299.

${ }^{9}$ DEEC, EP, T. 16, 1768, Fs. 664-666.

10 DEEC, EP, T. 17, 1770, Fs. 169-173.

11 Además de los hogares urbanos, la familia contaba con algunas estancias y otros establecimientos rurales que abarcaban grandes cantidades de tierras y ganados, y entre la mano de obra allí empleada se contaban algunos esclavos. En Santa Fe poseían la estancia de San Miguel (ubicada al sur de la ciudad) y la de Añapiré (ubicada al norte), y en el sur de la actual provincia de Entre Ríos poseían la estancia de San José de Gualeguaychú (Tarragó, 1996).
} 


\section{Gonzalo Cáceres}

Otro dato que se desprende del manuscrito está vinculado con los matrimonios. En él se registraron un buen número de uniones dentro del plantel de esclavos, algunas de las cuales, como se verá más adelante, se dieron entre esclavos de la familia y otras entre esclavos con personas libres, particularmente entre esclavas con hombres libres. Como ya han planteado algunas investigaciones, la importancia dada al matrimonio legítimo respondía tanto a las presiones que la Iglesia ejercía sobre los propietarios para evitar que la promiscuidad de los esclavos condujera a "desordenes" entre la población (Suárez, 1993) como a una estrategia de los amos para arraigar a los cautivos y así evitar las fugas (Albores, Mayo \& Swennwy, 1994; Baravalle, 2001). Pero el matrimonio cumplía otra función importante: proveía de mano de obra. La constitución de familias garantizaba a los amos no solo la incorporación de nuevos esclavos al patrimonio a través de los nacimientos de las mujeres esclavizadas, sino que también les permitía retener para su servicio a los cónyuges libres e hijos de sus esclavos. Era habitual que los esclavos convivieran con sus parejas libres e hijos en las casas de los amos, y que éstos, aprovechando esa situación, los emplearan como mano de obra en esas propiedades (Guzmán, 1997; Zacca, 1997) ${ }^{12}$.

Es preciso señalar que desde el punto de vista de los esclavizados, contraer matrimonio con una persona libre garantizaría, en el caso de los esclavos varones, la libertad jurídica de sus hijos, en tanto que para las esclavas mujeres, "esa unión podía significar una protección económica adicional, social y emocional, y un medio de movilidad para su descendencia" (Guzmán, 1997: 231). Este comportamiento matrimonial fue bastante frecuente en la ciudad. De los 502 matrimonios que se concretaron entre 1750 y 1810 en los que al menos uno de los contrayentes era esclavo, en 227 oportunidades las mujeres se casaron con una persona libre, mientras que los varones lo hicieron en 195 ocasiones (Cáceres, 2019b). Estos datos sugieren que más allá de las presiones que debieron existir por parte de los propietarios, los esclavos pudieron mejorar su situación social a través de tales uniones ${ }^{13}$.

Las tareas que los esclavos cumplían en las distintas propiedades de los Andino eran variadas. Los registros indican que algunos estuvieron abocadas a las labores en la estancia San Miguel, la propiedad más importante de la familia, adquirida por Manuel Ignacio en 1774 de los bienes de la expulsa Compañía de Jesús (Tarragó, 1996). Por el perfil ganadero de esta estancia, predominaba la cría de mulas y vacas, orientada a la producción de cueros, pero también se generaban algunos cereales, como el trigo, y probablemente también se procedía allí mismo a su molienda

\footnotetext{
12 Por ejemplo, como veremos más adelante, la esclava Dominguita, hija de Dominga esclava y de Canciano Cari libre, se casó con un pardo libre, llamado Francisco Orosco, sastre, oriundo de Tucumán, que en el censo de la ciudad de 1816-17 aparece como agregado en la casa de Manuel Ignacio.

${ }^{13}$ Isabel Zacca (1997) ha observado un comportamiento matrimonial similar para el caso de Salta entre los años 1766-1800. De los 291 matrimonios que encuentra en los que al menos uno de los cónyuges era esclavo, 106 se dieron entre esclavas con hombres libres, 97 entre esclavos con mujeres libres, y 89 entre esclavos.
} 


\title{
Trayectorias familiares y experiencias individuales: el caso de los esclavizados de los Diez de Andino en Santa Fe (1763-1822)
}

(Tarragó, 1996). Hombres, mujeres y niños se dividían entre éstas y otras actividades, conviviendo con peones y conchabados libres con los que en ocasiones se unieron y formaron nuevas familias. Al frente de este establecimiento se encontraba Hipólito Cabrera, un mulato que hasta su muerte en 1780, ofició como su capataz. Que un esclavo ocupara este puesto no era extraño, Carlos Mayo (1997) ha reconstruido la importante labor del esclavo Patricio de Belén como capataz en la estancia Las Vacas, cuya posición excepcional fue adquirida según este historiador gracias a su habilidad para hacerse obedecer por los demás trabajadores y a su puntualidad en el cumplimiento de las tareas. Es posible que a Hipólito Cabrera su amo le confiara el puesto por poseer ese tipo de cualidades, y algunas otras más, como el saber mediar en los conflictos que se pudieran suscitar entre los trabajadores, que eran una realidad en los puestos de estancia. Sobre estas diferencias podemos citar el relato que el esclavo Pedro José realizó en una carta enviada a Manuel Ignacio en 1801:

\begin{abstract}
“Mi estimado amo, después de saludar a Vuestra Merced y puesto a sus pies digo, que enterado de la escuela de su Merced le doy satisfacción para que sepa no es conforme le han informado sino al contrario, porque no hay fuerza que no me ocupen que no esté yo pronto al servicio de su Merced...ahora es ocasión que Vuestra Merced sepa de la forma que me tratan mis compañeros, todos me tienen entre ojos. El mes pasado el negro Antonio por haberle dicho en la puerta del corral por qué habían entrado toda la yeguada que se estropeaban las mulas chicas me atropelló dicho Antonio diciéndome que quién me metió a mí, me agarró de los ponchos, me derribó de a caballo y se me sentó encima y me dio golpes y me sacó el cuchillo y desafiándome que saliera atrás de la ensenada, y no quise salir por evitar yo otras cosas que me están sucediendo a cada paso"14.
\end{abstract}

Otros esclavos estuvieron abocadas a labores en la casas de los Andino en la ciudad. Allí, como en otros espacios urbanos rioplatenses, las tareas eran por lo general domésticas y artesanales. Además de cocinar, lavar, limpiar las casas o atender los huertos y los frutales, algunos cautivos con oficio cubrían tareas más especializadas (Andrews, 1989; Bernand, 2001; Goldberg \& Mallo, 2005a). Entre los esclavos de la familia se encuentran María y Paula, negras portuguesas, ambas costureras; Antonio, zapatero; Tomás, negro criollo, herrero; y Florencio, también zapatero. Algunos de estos oficios fueron incentivados y hasta promovidos con el objetivo de obtener un ingreso adicional del trabajo especializado de los esclavos. El historiador Eduardo Saguier (1989) ha señalado que en el Río de la Plata existió una esclavitud de tipo estipendiaria en la que los amos obligaban a sus esclavos a contribuir con un tributo individual llamado jornal. Según este autor, para lograr hacerse de ese tributo, los esclavos se veían obligados a alquilar su fuerza de trabajo o bien a producir mercancías para vender en el mercado colonial (Saguier, 1989: 44). Tal fue el caso de Florencio, quien en 1819, en ejercicio de su oficio de zapatero, "trabajando en las gorras y botas de los oficiales", escribía a Manuel Ignacio desde Paraná

${ }^{14}$ AGPSF, CDA, Leg. 62, Carp. 2, F. 2-3. 


\section{Gonzalo Cáceres}

señalando: "mi amo y señor, con Don Cayetanito Echague remito seis pesos que es todo lo que he podido alcanzar y aun dos pesos he pedido prestados para enterar dichos seis pesos"15.

Como señalamos al comienzo, en el manuscrito Manuel Ignacio se ocupó de registrar entre otras cosas los decesos de sus esclavos, señalando en ocasiones sus causas. Entre los factores de mortalidad que registró destacan las enfermedades infecciosas, como la viruela y el sarampión, pero también el trabajo extenuante, los accidentes e incluso los traumas ocasionados por la travesía forzada por el Atlántico.

Al respecto podemos comenzar citando la tragedia de Manuel, negro africano, que según el manuscrito, "murió loco" en 1767, a los 22 años ${ }^{16}$. Es posible que para Manuel, como para tantos otros cautivos, la crueldad del viaje Atlántico y el desarraigo obligado se hayan convertido en una situación difícil de sortear. En efecto, la ruptura de sus lazos parentales, la imposición de una nueva cultura, una nueva lengua, una nueva religión y nuevos formatos familiares, pudieron haber generado en él secuelas emocionales severas, sin contar las consecuencias derivadas del hacinamiento, la precariedad sanitaria y la inadecuada alimentación en los buques negreros que también debieron generarle todo tipo de traumas físicos (Klein, 2002). Todos estos factores posiblemente determinaron su temprana y trágica muerte.

Ciertamente, la demencia no siempre era el resultado de la travesía Atlántica. La esclavitud misma, en tanto sistema deshumanizante y alienante, que suponía que la vida de unos pertenecía a otros, pudo haber repercutido drásticamente en la psiquis de la esclava Silveria, que según el manuscrito, "murió deschavetada de enfermedad"17.

Otra muerte asociada a factores emocionales fue la de Ignacio Flores, esclavo que había ingresado a la familia Andino como parte de la dote recibida por la esposa de Manuel Ignacio, Josefa Terán. Según se señala en el documento, Ignacio Flores "murió de pasmo" en la estancia San Miguel el 22 de enero de 177718. En aquella época, el "pasmo" estaba asociado a una situación traumática, a un evento estresante -que en este caso no podemos precisar-, caracterizado por una sensación de espanto y miedo profundo (Covarrubias, 1611) que, en el caso de Ignacio, demostró ser letal. Las enfermedades infecciosas, como adelantamos, fueron otro factor importante en la muerte de una parte considerable de los esclavizados de la familia Andino. Los brotes de estas epidemias fueron bastante frecuentes en la ciudad durante el siglo XVIII y las primeras décadas del siglo XIX ${ }^{19}$. Manuel Ignacio gastó mucha tinta en dar cuenta de ellas en su manuscrito y las actas del cabildo de Santa Fe registran a estas

\footnotetext{
15 AGPSF, CDA, Leg. 62 Carp. 2, F. 19.

16 AGPSF, CDA, Leg. 62, Carp. 1, F. 2.

17 AGPSF, CDA. Leg. 62, Carp. 1, F. 4.

18 AGPSF, CDA. Leg. 62, Carp. 1, F. 8v.

${ }^{19}$ Sobre dos grandes epidemias que afectaron la región rioplatense y el Tucumán en la primera mitad del siglo XVIII véase Frías \& Monserrat (2017).
} 


\section{Trayectorias familiares y experiencias individuales: el caso de los esclavizados de los Diez de Andino en Santa Fe (1763-1822)}

“pestes" en $1778-79,1783,1789,1791-92,1800-03$ y en $1814^{20}$. Por su naturaleza contagiosa, tales enfermedades afectaron al conjunto de la población, aunque en mayor medida a los sectores más pobres, que vivían en condiciones habitacionales e higiénicas precarias y con dietas inadecuadas (Goldberg \& Mallo, 2005b). El brote de viruelas de 1817 del que da cuenta Manuel Ignacio -no se registra en las actas del cabildo-, como se verá, fue el que más vidas de sus esclavos se cobró, y afectó particularmente a las familias esclavas, provocando gran mortalidad en los niños.

Algunos datos registrados en el manuscrito nos permiten conocer los efectos que estas enfermedades provocaban en las personas. Por ejemplo, Hipólito, el capataz de la estancia San Miguel, "murió de una peste general de fluro (sic) de sangre por las narices"21. No menos dramática fue la muerte del mulatillo Pedro José22, que falleció por "una grave enfermedad" -no se especifica cuál- que le produjo "un sangrado en los tobillos"23.

La documentación da cuenta de otras causas de muerte y también nos permite conocer detalles de los padecimientos de los esclavizados. El trabajo agotador pudo ser causante del fallecimiento de Domingo, un negro africano que Manuel Ignacio había recibido de Don Jerónimo Jaqués en pago de 700 pesos que este vecino había quedado debiendo a su finado padre. Este esclavo, según puede leerse en el manuscrito, "murió en la chacra en la huerta estando arando en 1792"24. La muerte de Tomás, "negro criollo de temporalidades", fue al parecer bastante trágica. En 1780 quedó ciego y en un intento por curarlo Manuel Ignacio lo mandó a Buenos Aires, con un médico portugués de apellido Lagosta, "de mucha fama", sin embargo, la intervención no tuvo éxito. Andino señala en el manuscrito: "me ganó 50 pesos fuera de mantención y otros costos [y] me lo volvió peor y murió a los pocos meses, año de 1782"25. La muerte de la esclava Polonia fue igual de dramática. Falleció luego de una larga agonía, "a los 4 meses de mordedura de perro rabioso que no se curó, que la ama del perrito cusco (sic) aseguraba no rabiaba, pero murió rabiando" 26 . Finalmente, otra de las muertes violentas registradas en el manuscrito fue la de Evaristo, hijo de María Antonia, negra africana y esclava de la familia, el cual "se ahogó en el río enfrente el año 1768"27.

\footnotetext{
${ }^{20}$ AGPSF, Actas del Cabildo de Santa Fe, 1778-79, T. XIV B, XIV, Fs. 503-504v, Fs. 513v-514v, Fs. 529531, Fs. 552-553, Fs. 556 y v.; 1783, T. XV, XV, Fs. 101 y v.; 1789, T. XV B, XV Fs. 371v-373v.; 1791-92, Varios documentos, Leg. 20, Fs. 34-36, T. XVI A, XVI Fs. 162v-f. 164v, Fs. 167v-170; 1800-03, Expedientes Civiles, T. 149, Fs. 24v-27v, Fs. 33-34v, T. XVII A, XVII Fs. 78-79, Fs. 122-124, Fs. 130v131v, Fs. 134-135v.; 1814, Actas Recuperadas Caja 1, Acuerdos de 1814, Fs. 52-53v.

${ }^{21}$ AGPSF, CDA. Leg. 62, Carp. 1, F. 8.

${ }^{22}$ Este esclavo había sido adquirido por Manuel Ignacio como parte de pago de una deuda que con él tenía Don Juan de Setúbal, un vecino de la ciudad.

${ }^{23}$ AGPSF, CDA, Leg. 62, Carp. 1, F. 7.

${ }^{24}$ AGPSF, CDA, Leg. 62, Carp. 1, F. 7.

${ }^{25}$ AGPSF, CDA, Leg. 62, Carp. 1, F. 8.

${ }^{26}$ AGPSF, CDA, Leg. 62, Carp. 1, F. 3v.

${ }^{27}$ AGPSF, CDA, Leg. 62, Carp. 1, f. 2.
} 


\section{Gonzalo Cáceres}

\section{Historias de familias esclavas}

Hasta el momento no se han reconstruido en Santa Fe genealogías de familias esclavas, por lo que la fuente que nos ha legado Manuel Ignacio es muy valiosa en ese sentido. Aunque sujeta a la memoria y a los olvidos del autor, la misma constituye un punto de partida insoslayable para proponer un ejercicio de reconstrucción de las historias de familias enteras que por generaciones estuvieron sujetas a servidumbre. En esa línea, la información aportada por el manuscrito será triangulada y confrontada con datos provenientes de los archivos de gobierno, eclesiásticos y notariales con el objetivo de analizar las trayectorias de las tres grandes familias esclavas que estuvieron bajo el dominio de los Andino: la de Juana y Juan, la de Catalina y Antonio, y la de Teresa e Hipólito Cabrera.

\section{La familia de Juana “bozal” y Juancho “cordobés”}

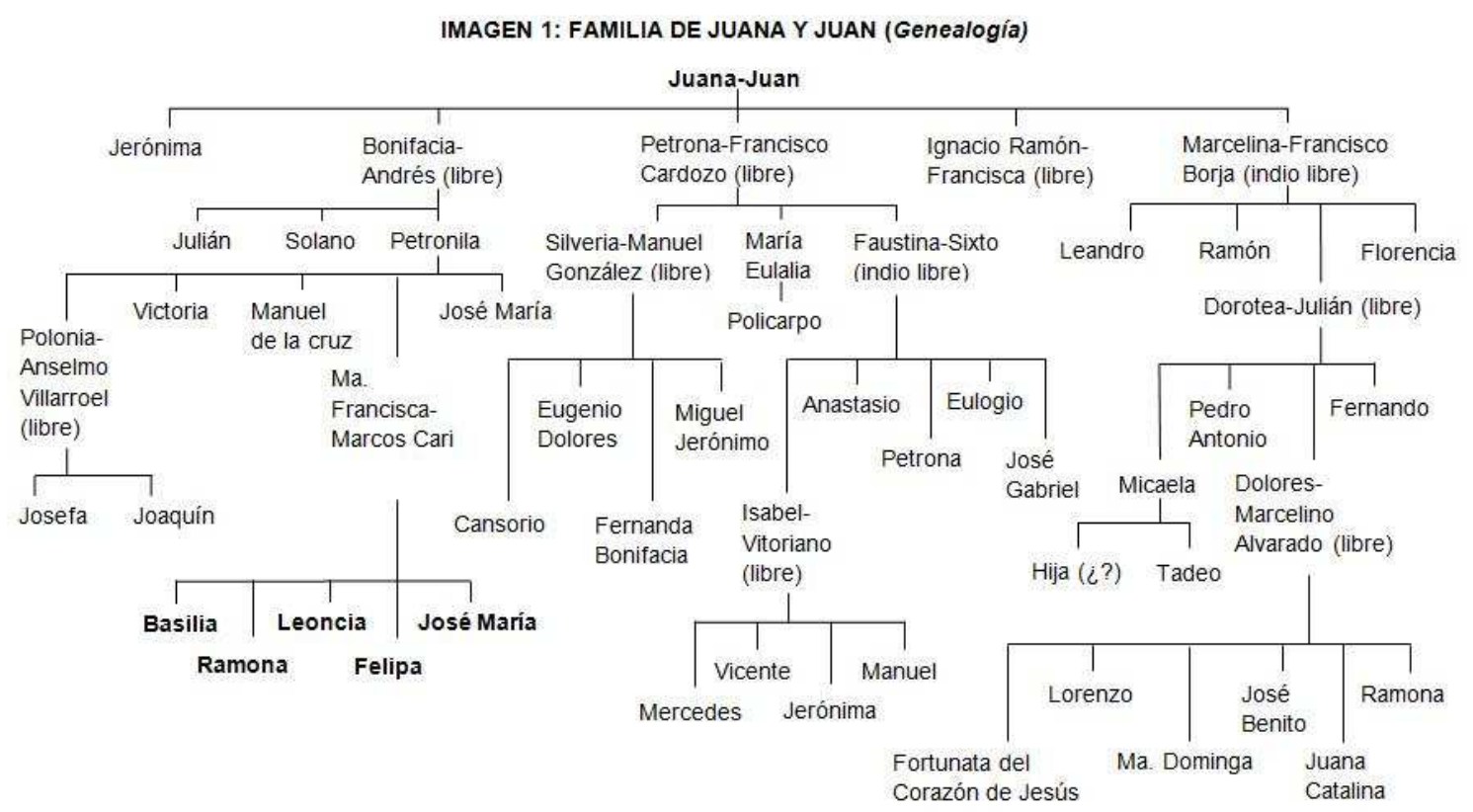

Fuente: CDA. Legajo 62, carpeta 1, f. 1-9, AGPSF; Informaciones Matrimoniales, Actas de Bautismo, Matrimonios y Defunciones, AASF.

La historia de esta familia se remonta a los tiempos en que vivía Don Bartolomé. Los primeros indicios de las vidas previas de Juana y Juan antes de llegar a la casa de los Andino lo aporta su expediente matrimonial28, labrado el 1 de julio de $1741^{29}$. Ese día, ambos esclavizados comparecieron ante el juez eclesiástico Don Pedro

\footnotetext{
${ }^{28}$ Las denominadas "informaciones matrimoniales" eran documentos que se labraban a las personas forasteras o a aquellas que, siendo residentes, se habían ausentado por un tiempo prolongado de la ciudad a los efectos de confirmar su estado soltero. Antes de autorizar los matrimonios la Iglesia católica exigía a los contrayentes, generalmente a los hombres, que presentaran una serie de testigos (entre 3 y 4) que dieran cuenta de su soltería. Un notario realizaba a cada uno de ellos una serie de preguntas relacionadas con su pasado y el de los novios y dejaba registro de cada respuesta. Una vez evaluados los testimonios y de no existir impedimento comprobado, el juez eclesiástico otorgaba la licencia pertinente para la celebración de la unión.

${ }^{29}$ Archivo de la Arquidiócesis de Santa Fe (AASF), Santa Fe, Argentina. Expediente matrimonial de Juana y Juan Andino. 1 de julio de 1741. Información Matrimonial, 1737-1755, expediente nº 56.
} 


\section{Trayectorias familiares y experiencias individuales: el caso de los esclavizados de los Diez de Andino en Santa Fe (1763-1822)}

Rodríguez solicitando licencia para poder contraer matrimonio. Como Juana y Juan eran forasteros, la Iglesia les exigía que presentaran una serie de testigos que confirmaran que no existía impedimento para que se llevara a cabo su unión. A partir del relato de estas personas -entre los que se cuenta el del propio Bartolomées posible inferir cuál había sido el derrotero de cada uno de ellos hasta llegar a Santa Fe.

Juan era un negro "criollo" natural de Córdoba que, a juzgar por el testamento de Bartolomé, para 1741 debió haber tenido unos 20 años de edad y ya era viudo de primer matrimonio. Antes de ser adquirido por los Andino, en 1740, había asistido en la estancia Santa Catalina (Córdoba), perteneciente a la Compañía de Jesús. Quien ofició de intermediario en la operación de compraventa entre la Compañía y Don Bartolomé fue Don Domingo de Basavilbaso, un importante comerciante vasco, residente en Buenos Aires, con quien Bartolomé hacía negocios y a quien -como a otros tantos comerciantes- encomendaba ciertas diligencias fuera de la ciudad (Tarragó, 1994, 2010; Barriera \& Tarragó, 2005). El historiador Jorge Troisi Melean (2012) ha planteado que rara vez los jesuitas se desprendían de sus esclavos, que ello ocurría por lo general cuando éstos evidenciaban un comportamiento negativo. Según el autor, la política jesuita en relación a los esclavos considerados "malos", esto es, aquellos que realizaban todo tipo de manifestaciones de resistencia, era la venta: "el esclavo conflictivo era el problema y si se lo vendía, tanto uno como el otro desaparecían" (Troisi Melean, 2012: 88). Aunque no tenemos certezas de que Juan haya sido vendido por los padres de la compañía como castigo por haber cometido ese tipo de actos, su comportamiento futuro nos da a pensar que algo de ello pudo haber ocurrido, ya que "murió fugitivo en la jurisdicción de Córdoba"30, en 1794. Juana, por su parte, era africana, de nación Angola, también de unos 20 años de edad. Por el expediente sabemos que antes de llegar a Santa Fe había residido en Corrientes, y que antes de eso había estado en Buenos Aires. Como tantos otros cautivos, Juana debió haber llegado al puerto de Buenos Aires directamente desde África o por alguno de los circuitos costeros que conectaban al Río de la Plata con el imperio del Brasil, y desde allí fue internada en la ciudad de Corrientes donde fue bautizada ${ }^{31}$.

Juana y Juan se casaron el 24 de julio de $1741^{32}$ y juntos formaron una extensa familia cuyas generaciones permanecieron ligadas a los Andino incluso luego de la muerte de Manuel Ignacio. El desenlace de la vida de Juan, huyendo de su amo, nos obliga a reflexionar acerca de los motivos de su unión con Juana. ¿Por qué se

\footnotetext{
${ }^{30}$ AGPSF, CDA, Leg. 62, Carp. 1, F. 2. El "camino ilegal” hacia la libertad, como han demostrado algunas investigaciones sobre el Río de la Plata, fue una opción y una elección para muchos esclavizados. Al respecto ver: Saguier (1995), Dimunzio \& García (2006), Candioti (2018), Moriconi (2018). Como veremos a lo largo de este trabajo, un buen número de los esclavos de los Andino utilizaron esa "vía" de emancipación.

${ }^{31}$ Sobre el tráfico atlántico al Río de la Plata véase Borucki (2017). Sobre el proceso de internación de los esclavizados en el interior rioplatense véase Rosal (2009).

${ }^{32}$ AASF, Acta de matrimonio de Juana y Juan Andino. 24 de julio de 1741. Libro de Matrimonios, 17341764, F. 6.
} 


\section{Gonzalo Cáceres}

casaron? ¿Fue una elección suya o existieron presiones de parte de su amo para que esto ocurriera? Escaparse era también abandonar a su familia. Si hubo una política de arraigo a través del matrimonio, en este caso, no tuvo éxito. La suerte de Juana, como la de la mayoría de sus hijas, nietas y bisnietas, no fue la mejor. Acabó sus días como esclava de los Andino. Luego de una extensa vida a su servicio, murió en 1802. Antes de que las vidas de Juana y Juan tomaran caminos distintos, la pareja tuvo cinco hijos (Jerónima, Bonifacia, Petrona, Ignacio Ramón y Marcelina) y, como intentaremos mostrar, las historias de cada uno de ellos dan cuenta de experiencias de vida muy diversas.

La mayor de entre sus hijos, Jerónima, murió -según el manuscrito- en 1763 a la edad de 26 años. No hemos encontrado en los registros parroquiales el acta correspondiente a este deceso y llama la atención que en el testamento de Don Bartolomé no se la mencionara entre los esclavizados declarados como sus bienes. De su vida anterior no tenemos mayores datos.

Bonifacia ${ }^{33}$, su hermana, se casó con una persona libre, de nombre Andrés, y tuvieron por hijos a Julián, Solano y Petronila. Sobre Julián dice Manuel Ignacio: "nació en 1764 y se huyó en 1792, algunas noticias de que andaba de contrabandista en los campos de Montevideo"34. Su fuga, como la de su abuelo Juan, tuvo un notable éxito. Dos décadas después no habían podido capturarlo y seguían buscándolo. En un poder de 1809 encontramos a Manuel Ignacio habilitando a Don Juan Domingo de las Carreras:

"Para que solicite unos esclavos míos que andan fugitivos en [Montevideo] y su jurisdicción llamados Julián y Ramón, de cuyas señas le instruyo y los pueda vender a precios equitativos" 35 .

Como veremos más adelante, Julián y Ramón eran primos.

Solano nació en 1766, y como su hermano también huyó del dominio de su amo. Lo hizo en dos ocasiones, aunque con menos suerte que Julián dado que en las dos oportunidades fue capturado: "la primera se trajo de Los Arroyos, la segunda se agarró en Buenos Aires, y en la cárcel enfermo, y en el hospital, se vendió año 1794 en precio de 180 pesos por salir de él"36. Las tachas de fugitivo y enfermo posiblemente determinaron que el precio en el que se vendiera fuera bastante menor al precio promedio de los esclavizados para la época. Un esclavo a la edad en la que fue vendido Solano (28) valía en Santa Fe en promedio 261,22 pesos (Cáceres, 2019a: 16).

\footnotetext{
${ }^{33}$ Según se señala en el manuscrito, Bonifacia murió en 1766. Este es uno de los tantos datos que nos hablan de una cierta fragilidad en la memoria de Manuel Ignacio, ya que él mismo indica que la hija de Bonifacia (Petronila), nació dos años más tarde de ese supuesto deceso. Desafortunadamente no hemos encontrado el acta de defunción de esta esclava por lo que no sabemos cuál fue su destino. Tampoco hemos encontrado las actas de bautismo de sus hijos para confrontarlas con el documento dejado por Manuel Ignacio.

${ }^{34}$ AGPSF, CDA, Leg. 62, Carp. 1, F. 3.

${ }^{35}$ DEEC, EP, T. 22, 1809, Fs. 217-218.

${ }^{36}$ AGPSF, CDA, Leg. 62, Carp. 1, F. 3.
} 


\section{Trayectorias familiares y experiencias individuales: el caso de los esclavizados de los Diez de Andino en Santa Fe (1763-1822)}

Petronila, la hija menor de Bonifacia, nació en 1768 y tuvo cinco hijos naturales (Polonia, María Francisca, José María, Victoria y Manuel de la Cruz), aunque no sabemos con quién. Como veremos, la ilegitimidad de los nacimientos se dará con otras esclavas de la familia. Lamentablemente las fuentes con las que contamos no nos permiten saber bajo qué circunstancias se procrearon esos niños, es decir, si fueron resultado de relaciones ocasionales, de uniones informales o si fueron producto de alguna otra situación. Petronila fue vendida en 1802 junto a Victoria que por entonces tenía 7 años- y a Manuel de la Cruz "de pechos" en 580 pesos, a Don Malaquías Duarte Neves ${ }^{37}$.

¿Qué pasó con los otros hijos de Petronila? Sabemos que a Polonia, nacida el 20 de febrero de 1786, Manuel Ignacio la dio en dote a su hija Ramona Andino, casada con el catalán José Puyol. El 9 de octubre de 1812 Polonia contrajo matrimonio con Anselmo Villarroel, un pardo libre natural de Córdoba ${ }^{38}$. Tuvieron por hijos a Josefa, a Joaquín y a Valeriana, nacidos en 1805, 1811 y 1814 respectivamente $^{39}$. Josefa fue otorgada por Manuel Ignacio a su yerno (José Puyol) como pago por una deuda de 200 pesos contraída con él. En el censo de 1816-17, fue registrada con el apellido de su nuevo amo. Joaquín también fue separado de su madre y donado por Josefa Terán (esposa de Andino) a uno de sus nietos, Francisco María Puyol, y en el mismo padrón fue registrado con su nuevo apellido. Valeriana en cambio no figura censada ni en casa de los Puyol, ni en la de los Andino y no tenemos más información sobre su destino. Polonia murió el 10 de abril de 1816 y fue sepultada en el convento de San Francisco, aun siendo esclava de Doña Ramona Andino 40.

María Francisca, hermana de Polonia e hija de Petronila, se casó con Marcos José Cari, "indio criado"41, y tuvieron cinco hijos: Basilia, Ramona, Felipa, Leoncia y José María. Todos sufrieron sarampión y viruelas y todos fueron vacunados por su amo. Tres mujeres fallecieron a edad temprana. Basilia a los 3 años, de sarampión, en 1808, y Ramona y Felipa a los 7 y a los 3 años respectivamente, ambas de viruelas

\footnotetext{
37 Don Malaquías Duarte Neves era un cura que participaba activamente en el mercado esclavista de la ciudad (Candioti, 2016a). En un acta matrimonial del 22 de diciembre de 1811, encontramos a Victoria contrayendo matrimonio con Pedro José Báez, también esclavo de Duarte Neves. AASF, Acta de matrimonio de Victoria Andino y Pedro José Báez. 22 de diciembre de 1811. Libro de Matrimonios, 1805-1819, F. 169.

38 AASF, Acta de matrimonio de Polonia Andino y Anselmo Villarroel. 9 de octubre de 1812. Libro de Matrimonios, 1805-1819, F. 187.

39 Valeriana nació casi un año después de que la Asamblea Constituyente de 1813 sancionara la llamada "libertad de vientres". AASF, Acta de bautismo de Valeriana Andino. 30 de enero de 1814. Libro de Bautismos, 1811-1814, F. 264. Si bien en el acta no se la va a clasificar como "liberta", sí se dejará constancia de que era hija de esclava y que por tanto el bautismo era gratuito como se establecía en el artículo 20 del "Reglamento para educación y ejercicio de libertos". Es importante destacar que la ley de vientre libre no liberaba inmediatamente a los hijos de las esclavas sino que los introducía en la condición de libertos. Como tales, debían servir a los amos de sus madres hasta los 16 años las mujeres (si no se casaban antes) y hasta los 20 los varones (Candioti, 2016b).

${ }^{40}$ AASF, Acta de defunción de Polonia Andino. 10 de abril de 1816. Libro de Defunciones, 1815-1816, F. 29.

41 AASF, Acta de matrimonio de María Francisca Andino y Marcos José Cari. 17 de diciembre de 1810. Libro de Matrimonios, 1805-1819, F. 144v. Marcos, como veremos, en realidad era esclavo, hijo de Dominga Andino, esclava de la familia, y de Canciano Cari, indio libre.
} 


\section{Gonzalo Cáceres}

en San Miguel, en 1817. Sobrevivieron Leoncia, que nació en 1818 y fue bautizada en San Lorenzo ${ }^{42}$, y José María, que fue tomado para su servicio por uno de los hijos de Manuel Ignacio, Rafael. José María siguió el mismo camino que sus tíos Julián y Solano y que su abuelo Juan. Estando en servicio "se huyó de San Miguel 10 de diciembre de $1816^{\prime \prime 3}$ y no volvemos a tener información sobre su paradero, por lo que suponemos que se trató de otra fuga exitosa.

La historia de Petrona, hermana de Jerónima y Bonifacia, e hija de Juana y Juan, es igual de rica que la anterior. Se casó con un indio de las Misiones, llamado Francisco Cardozo $^{44}$ y tuvieron tres hijas: Silveria, María Eulalia y Faustina. Petrona tuvo una extensa vida al servicio de sus amos y murió en San Miguel el 17 de febrero de 1817. La mayor de entre sus hijas, Silveria, se casó con Manuel Asencio González, natural de Paraguay, libre, en $1800^{45}$. Según el manuscrito, esta esclava también murió en San Miguel, el 10 de febrero de 1817, una semana antes que su madre. Con Manuel tuvieron a Cansorio que murió niña ${ }^{46}$, y a Eugenio Dolores, Fernanda Bonifacia y Miguel Jerónimo que tuvieron vidas más largas. A Eugenio Dolores lo tomó Rafael por su criado, mientras que Miguel Jerónimo y Fernanda Bonifacia permanecieron en casa de Manuel Ignacio. Ambos fueron censados como esclavos de la familia en 1816-17.

María Eulalia, la segunda de las hijas de Petrona, tuvo un hijo natural, nombrado Policarpo, que nació en 1800, y Manuel Ignacio los vendió a ambos a Don Juan José Infante (comerciante), el 5 de diciembre de 1806 en 500 pesos ${ }^{47}$. En el censo de población encontramos a ella pero no a su hijo viviendo en la casa de su nuevo propietario y con su apellido.

Faustina, la última de las hijas de Petrona, fue madre tempranamente. A los 13 años tuvo una hija natural, Isabel, que nació en 1793 y que padeció viruelas y sarampión pero sobrevivió. Faustina se casó en 1796 con Sixto Verón, indio natural de Calchaquí del Río Carcarañá, perteneciente al curato de Coronda ${ }^{48}$. Con él tuvieron a Anastasio en 1801 (que Manuel Ignacio se lo dio a su hijo Claudio), a Petrona y a Eulogio que murieron niños, y en un acta de 1818 encontramos a Faustina y a Sixto bautizando en la Capilla del Rosario a un nuevo hijo, José Gabriel Verón Andino, "liberto" 49 . Isabel de Faustina se casó con Victoriano, libre, y tuvieron unos cuantos hijos, aunque las enfermedades fueron implacables con ellos. Mercedes, Jerónima y Manuela murieron con menos de 3 años de edad (Jerónima y Manuela por el brote

\footnotetext{
${ }^{42}$ En la zona de San Lorenzo los Andino poseían algunos terrenos y chacra (Tarrago, 1993). Es posible que esta familia haya articulado sus actividades entre esas propiedades y la estancia de San Miguel. 43 AGPSF, CDA, Leg. 62, Carp. 1, F. 3.

${ }^{44}$ AASF, Acta de matrimonio de Petrona Andino y Francisco Cardozo. 10 de abril de 1766. Libro de Matrimonios, 1764-1804, F. 73v.

${ }^{45}$ AASF, Acta de matrimonio de Silveria Andino y Manuel Asencio González. 9 de julio de 1800. Libro de Matrimonios, 1764-1804, Fs. 500v-501.

${ }^{46}$ Cansorio nació en 1800 y murió en 1805.

${ }^{47}$ DEEC, EP, T. 21, 1806, Fs. 304-306.

48 AASF, Acta de matrimonio de Faustina Andino y Sixto Verón. 6 de agosto de 1796. Libro de Matrimonios, 1764-1804, Fs. 414v-415.

${ }^{49}$ AASF, Acta de bautismo de José Gabriel Verón Andino. 13 de abril de 1818. Libro de Bautismos, 1815-1825, F. 96v.
} 


\section{Trayectorias familiares y experiencias individuales: el caso de los esclavizados de los Diez de Andino en Santa Fe (1763-1822)}

de viruelas de 1817, en San Miguel). El único en sobrevivir a esa enfermedad fue su hijo varón, Vicente, que había nacido en 1812.

La historia de Ignacio Ramón, el único hijo varón de Juana y Juan, es bastante particular. Perteneció como sus hermanas mayores a Don Bartolomé y pasó por herencia a manos de Manuel Ignacio, con tan solo 14 años. El 17 de mayo de 1767 contrajo matrimonio con María Francisca Casco, natural de la ciudad de Santa Fe y criada de Doña Francisca Casal ${ }^{50}$. Decimos que su historia es particular porque Manuel Ignacio en 1770 lo vendió en 250 pesos a Don Gabriel de Quiroga ${ }^{51}$ para luego volverlo a comprar en 1781 a Don Fernando de Aguirre, yerno de Quiroga y heredero de los bienes de su difunta esposa, Doña María Lucía de Quiroga, en 300 $\operatorname{pesos}^{52}$. Contrariamente a lo ocurrido con otros integrantes de su familia, que optaron por las fugas como forma de liberarse del cautiverio, Ramón optó por el camino de la adaptación y se manumitió por la vía legal ${ }^{53}$. El 14 de abril de 1801 Ignacio Ramón accedió a su libertad pagando por ella. En la escritura otorgada por su amo puede leerse: "su criado...que le ha servido fielmente ha solicitado le conceda su libertad en 300 pesos" 54 . El monto solicitado se condice con el valor de compra de Andino a Aguirre, y si bien no hubo cargas especiales para dificultar la autocompra, tampoco se le concedió a Ramón una disminución en el precio por su libertad. Lo cierto es que este esclavo tenía algún margen de acción para acumular "peculio" en pos de su manumisión, posiblemente como resultado del despliegue de ciertas estrategias como el buen comportamiento para con su amo. No sabemos a través de qué industria Ramón consiguió reunir el dinero, en la documentación no se menciona si poseía algún tipo de oficio. Lo que sí es claro es que a Ramón hacerse de esa suma le llevó mucho tiempo y ello (como lo son las fugas) es una evidencia cierta de que para los esclavizados la libertad era un objetivo deseado y buscado. Por otro lado, no podemos dejar de llamar la atención sobre la relación manumisiónedad, ya que al momento de concretar su libertad, Ramón contaba con 52 años. Aunque no lo podemos probar, es posible que Manuel Ignacio haya aprovechado la oportunidad para desprenderse de un esclavo en edad avanzada -quizás poco productivo- antes de que se transformara en una potencial carga, después de todo él recibiría una considerable suma de dinero para reemplazarlo. La pronta muerte de Ramón, en 1805, resulta casi una confirmación de lo anterior.

La última de las hijas de Juana y Juan, Marcelina, también se casó con una persona libre, Francisco Borja, natural de Itapúa, Paraguay, posiblemente de origen

\footnotetext{
50 Se trata de una mujer libre que cumplía labores domésticas en la casa de esta vecina de Santa Fe. AASF, Acta de matrimonio de María Francisca Casco e Ignacio Ramón Andino. 17 de mayo de 1767. Libro de Bautismos y Matrimonios, 1761-1783, F. 80.

51 DEEC, EP, T. 17, 1770, Fs. 128-129.

52 DEEC, EP, T. 18, 1781, Fs. 454 y v.

${ }^{53}$ En las sociedades hispanoamericanas existieron predominantemente dos formas legales a través de las cuales los esclavizados pudieron acceder a la libertad: las manumisiones por gracia, mayormente otorgadas a través de testamentos, y las manumisiones por compra, que asumían la forma de auto-compras o que se concretaban con la ayuda de familiares o terceros (Johnson, 1976, 1978; Aguirre 1991; Lucena Salmoral, 1999; Ogass Bilbao, 2009; Valenzuela, 2017; Candioti, 2018). ${ }^{54}$ DEEC, EP, T. 20, 1801, Fs. 154-155.
} 


\title{
Gonzalo Cáceres
}

indígena ${ }^{55}$. Tuvieron cuatro hijos: Leandro, nacido en 1776; Ramón en 1780; Dorotea en 1789; y Florencia, de quién no tenemos registro, aunque debió haber nacido antes de 1789 que es cuando murió su madre. La historia de los hijos varones de Marcelina se parece a otros casos ya mencionados. Leandro huyó de la estancia San Miguel en 1799 y "se supo que pasó a la parte de Montevideo"56, como su primo Julián. El 20 de abril de 1805, a través de una correspondencia, Don Juan Bautista de Aguiar daba cuenta a Manuel Ignacio:

\begin{abstract}
"Que el señor comandante del cuerpo de blandengues de la frontera de Tacuarembó Chico aprehendió entre otros a un mulato José Alejandro Díaz ${ }^{57}$, que es esclavo de Vuestra Merced y pasaba por libre en estas compañías. Yo informado del caso me he resuelto a comprárselo a Vuestra Merced y desde luego pueda avisarme inmediatamente del precio de dicho esclavo y del sujeto que en Montevideo, o en Buenos Aires haya de recibir el dinero para librarlo prontamente, pues en esa de Santa Fe no tengo persona ni fondos para remitirle mi libranza"58.
\end{abstract}

Aguiar advierte en la misma correspondencia a Andino que el mulato pudo haber adquirido hábitos de vivir como libre y volver a huirse y que ese riesgo debe considerarse "para moderación del precio". Por carta del 27 de mayo de 1805, y a través de Don Pedro Votet, vecino de Buenos Aires nombrado en Montevideo, Manuel Ignacio contesta habilitando la venta en 250 pesos, aunque no obteniendo respuesta vuelve a escribir el 12 de noviembre reclamando se cumpla con lo pactado. La muerte repentina de Aguiar hizo que el pago nunca se efectuara y que Andino entrara en conflicto con la esposa del comprador ${ }^{59}$. En el manuscrito sintetiza tal situación señalando:

“El Doctor Don Juan Bautista de Aguiar me lo compró por carta y nunca me lo pagó y murió repentinamente, y la mujer Doña Ana Arco se resistió y yendo mi hijo Juan José con comercio lo vendió a un oficial en 250 pesos año 1810"60.

Ramón, hermano de Leandro huyó de la estancia de San Miguel en el año 1798. Como hemos señalado anteriormente, tanto él como su primo Julián fueron intensamente buscados por su amo. No sabemos si establecieron contacto, aunque es muy posible a juzgar por la documentación. Probablemente entre ellos (y otros esclavizados de la familia) se hayan tejido lazos de solidaridad que contribuyeron al éxito de tales acciones. Otra cuestión que pudo haber favorecido las fugas era el contexto de la estancia, menos vigilada y alejada de la órbita de control de los amos. Hasta ahora

\footnotetext{
55 AASF, Acta de matrimonio de Marcelina Andino y Francisco Borja. 23 de mayo de 1781. Libro de Bautismos y Matrimonios, 1761-1783, Fs. 164v-165.

56 AGPSF, CDA, Leg. 62, Carp. 1, F. 5.

${ }^{57}$ Por la correspondencia sostenida entre Andino y Aguiar sabemos que en realidad se trataba de Leandro y que éste utilizaba un nombre y un apellido falsos para no ser descubierto.

58 AGPSF, CDA, Leg. 62, Carp. 2, Fs. 4-5.

${ }^{59}$ AGPSF, CDA, Leg. 62, Carp. 2, Fs. 12-14.

60 AGPSF, CDA, Leg. 62, Carp. 1, F. 5.
} 


\title{
Trayectorias familiares y experiencias individuales: el caso de los esclavizados de los Diez de Andino en Santa Fe (1763-1822)
}

hemos visto que en general los esclavizados fugados cumplían labores en esas propiedades. Andino nos cuenta el derrotero de Ramón en el manuscrito:

\begin{abstract}
"Pareció primeramente en el Pilar aunque con varios encargos no se logró agarrarlo. Por segunda vez en Buenos Aires en casa de ejercicios y queriéndolo comprar 1803, y estando estudiando en el colegio mi hijo Pascual me escribió, se lo di ese para su servicio, a los pocos días me avisa que se le fue de casa de Doña Manuela Villarino, donde le cuidaban no habiendo más noticias"61.
\end{abstract}

Como se puede apreciar, este es otro ejemplo de una estrategia de resistencia y de emancipación que culminó con éxito.

Dorotea, hermana de Leandro y Ramón, se casó con una persona libre, Julián, natural del Paraguay, también de posible origen indígena, con quien tuvo cuatro hijos: Micaela nacida en 1798; Pedro Antonio en 180162; Dolores en 1806; y Fernando en 1808. Tres de ellos fueron censados en lo de Andino en 1816-17 (Micaela, Dolores y Fernando), no así Pedro Antonio. Éste había sido llevado por Pascual, hijo de Manuel Ignacio, a Chile para su servicio.

¿Qué sucedió con los hijos de Dorotea? Sabemos que Micaela tuvo una "mulatilla" que murió a los siete días -había nacido para San Cayetano, o San Bartolo (esto es, el 7 o el 24 de agosto) de 1817-y que luego, el 10 de junio de 1820, tuvo a Tadeo, ambos hijos naturales. En cuanto a Dolores y Fernando, hay que decir que, a diferencia de otros esclavos de la familia, ambos sobrevivieron a la peste general de 1817, gracias a que estaban vacunados. Andino se refirió a ello de la siguiente manera:

\footnotetext{
“Dolores de Dorotea... vacunada y dándoles a otros en la peste del año 1817 le inoculé y no le prendió por ser verdadera la vacuna. Fernando de Dorotea nació 30 de mayo de 1808, lo ha tomado para su paje mi hijo Juan José año 1814, vacunado, inoculado en la peste año 1817, y no le prendió por ser verdadera la vacuna"63.
}

Como se aprecia, existió una gran preocupación de parte del amo por la supervivencia de sus esclavos, explicable por el elevado costo que éstos tenían en el mercado (Rosal, 2009; Cáceres, 2019a). Las últimas huellas que encontramos de la historia de Dolores corresponden a una serie de actas de bautismos, defunciones y de matrimonio. Esta esclava pasó a manos de Manuela, hija de Manuel Ignacio, y antes de contraer matrimonio tuvo varios hijos naturales. En 1833 la encontramos bautizando a Fortunata del Corazón de Jesús64; en 1834 a Lorenzo "liberto"65; en

\footnotetext{
61 AGPSF, CDA, Leg. 62, Carp. 1, F. 5.

62 AASF, Acta de bautismo de Pedro Antonio Andino. 29 de junio de 1801. Libro de Bautismos, 18011805, Fs. 93v-94.

63 AGPSF, CDA, Leg. 62, Carp. 1, F. 5.

${ }^{64}$ AASF, Acta de bautismo de Fortunata del Corazón de Jesús Andino. 20 de abril de 1833. Libro de Bautismos, 1832-1837, F. 34v.

65 AASF, Acta de bautismo de Lorenzo Andino. 10 de agosto de 1834. Libro de Bautismos, 1832-1837, F. $139 \mathrm{v}$.
} 


\section{Gonzalo Cáceres}

1839 a María Dominga66; en 1843 a José Benito (que murió párvulo ese mismo año) ${ }^{67}$; y en 1844 a Juana Catalina ${ }^{68}$. En un acta de defunción de 1888, se menciona a Ramona, hija natural de Dolores Andino, fallecida a la edad de 56 años, nacida en 1832. Creemos que puede tratarse de otra hija suya69. En 1846 Dolores contrajo matrimonio con Marcelino Alvarado, sargento del batallón Guardia de la Federación, natural de la ciudad de Buenos Aires e hijo legítimo de Tadeo y Joaquina, negros ${ }^{70}$. Para entonces su situación no había cambiado dado que todavía seguía siendo esclava de los Andino.

\section{La familia de Catalina y Antonio “bozales”}

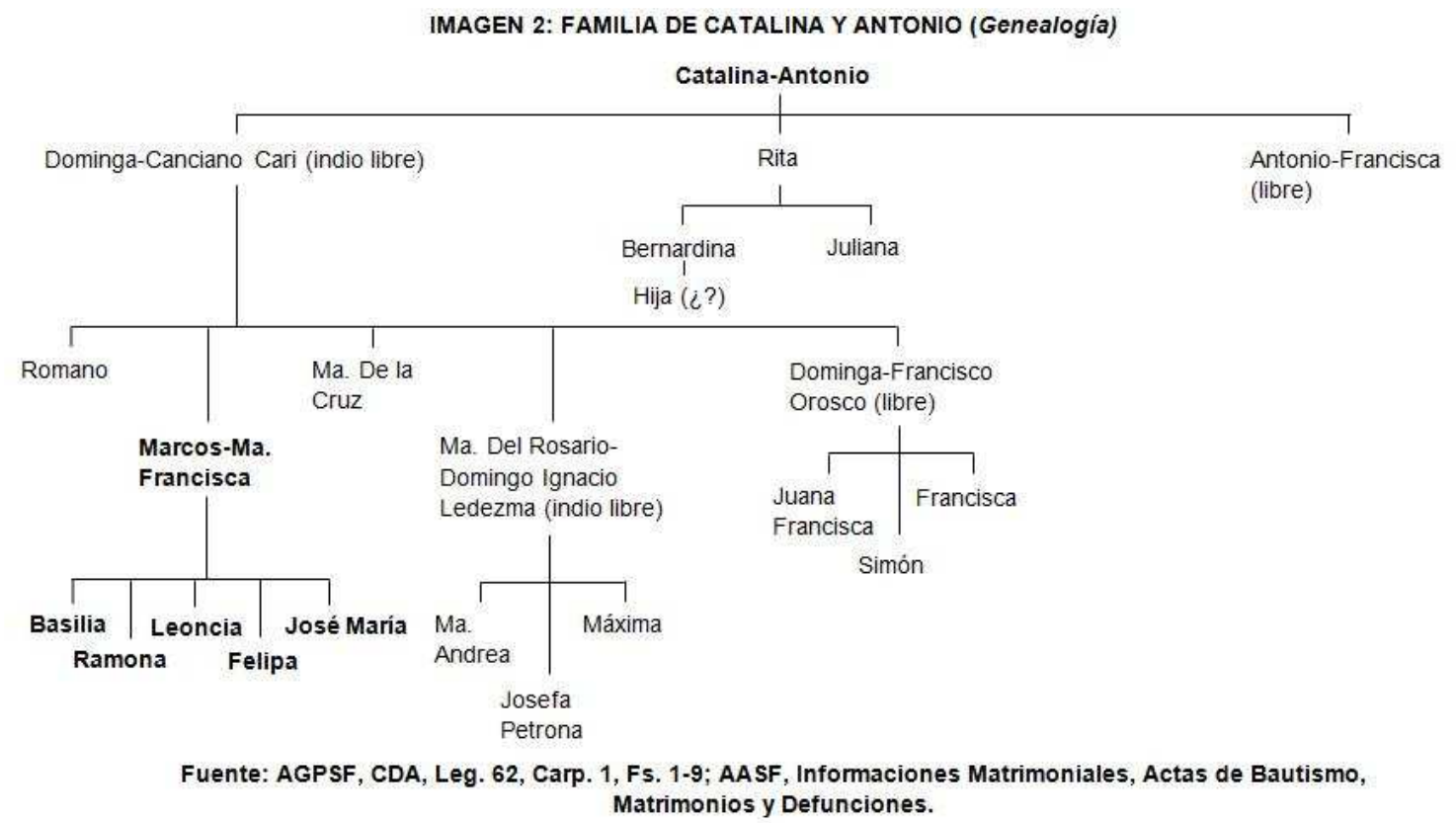

Como Juana y Juan, Catalina y Antonio pertenecieron a Don Bartolomé Diez de Andino y luego fueron heredados por su hijo Manuel Ignacio. Por su expediente matrimonial, con fecha del 20 de abril de 1759, sabemos que Antonio era africano, natural de Angola. Los dos testigos que presentó en aquella ocasión para que dieran cuenta de su soltería, Nicolás, criado en la casa del Maestre de Campo Don Juan de Lacoizqueta, y José Antonio Navarro, natural de Buenos Aires, declararon haberlo conocido en aquella ciudad, aprendiendo el oficio de zapatero y que cuando lo

\footnotetext{
${ }^{66}$ AASF, Acta de bautismo de María Dominga Andino. 12 de mayo de 1839. Libro de Bautismos, 18371843, F. 99.

${ }^{67}$ AASF, Acta de bautismo de José Benito Andino. 20 de marzo de 1843. Libro de Bautismos, 18371843, F. 399; AASF, Acta de defunción de José Benito Andino. 28 de abril de 1843. Libro de Defunciones, 1842-1845, F. 41v.

${ }^{68}$ AASF, Acta de bautismo de Juana Catalina Andino. 24 de noviembre de 1844. Libro de Bautismos, 1843-1847, F. 85.

${ }^{69}$ AASF, Acta de defunción de Ramona Andino. 4 de marzo de 1888. Libro de Defunciones, 18861891, F. 127.

${ }^{70}$ AASF, Acta de matrimonio de Dolores Andino y Marcelino Alvarado. 9 de noviembre de 1846. Libro de Matrimonios, 1838-1848, F. 115.
} 


\section{Trayectorias familiares y experiencias individuales: el caso de los esclavizados de los Diez de Andino en Santa Fe (1763-1822)}

trajeron a Santa Fe tenía unos 15 años ${ }^{71}$. También, como Juana, Antonio debió haber llegado a Buenos Aires por alguno de los circuitos de la trata Atlántica, donde fue comprado por Don Bartolomé. De Catalina sólo sabemos que era africana, y aunque no tenemos mayores noticias de sus orígenes, debió haber atravesado rutas similares a las de su esposo hasta llegar a Santa Fe. Se casaron el 29 de abril de ese mismo año ${ }^{72}$. Mientras que Antonio morirá en 1791, a los 58 años, Catalina, con 70 años y viuda, seguirá sirviendo como esclava en la casa de los Andino según el censo de 1816-17. Tuvieron por hijos a Dominga, Rita y Antonio, de cuyas historias hablaremos a continuación.

Dominga nació en 1766 y se casó con un indio de nombre Canciano Cari. Según el manuscrito, la pareja tuvo varios hijos que murieron chicos, quedando vivos cuatro, (Romano, Marcos, María del Rosario y “Dominguita")73. En el censo de 1816-17 rastreamos a Dominga y a sus dos hijas mujeres sirviendo como esclavas en la casa de Manuel Ignacio. Dominga murió en 1830 y en su acta de defunción no se hizo referencia alguna a su condición jurídica, su esposo Canciano aún vivía ${ }^{74}$.

¿Qué fue de la vida de los hijos de Dominga? Sabemos que Romano fue trocado por Andino con Ventura Coll por "un negrito bozal” en 180475, y que en 1807 fue vendido a otro vecino, Don Francisco Alsogaray, en 232 pesos $^{76}$, mientras que Marcos, su hermano, como hemos indicado más arriba, se casó con una nieta de Juana y Juan, María Francisca, produciéndose así la unión entre ambas familias esclavas.

Por su parte, María del Rosario, se casó en 1810 con Domingo Ignacio Ledezma, indio albañil77. Tuvieron varios hijos, y como ocurriera con otros esclavos de la familia, algunos perecieron por las enfermedades. María Andrea nació en $1811^{78}$ y fue una de las que sobrevivió a la peste de 1817 gracias a que estaba vacunada, en el censo también figuraba entre los esclavos de la casa de Andino. Josefa Petrona, su hermana, pese a estar vacunada, murió de viruelas a los 2 años, en 1817. En el censo figuraba como esclava en lugar de liberta -al igual que todos los libertos en Santa Fe (Candioti et. al., 2019). El 17 de noviembre de 1818 nació Máxima, fue bautizada al día siguiente en la Iglesia Matriz, sin embargo, víctima de viruelas falleció en la madrugada del 25 de octubre de 1819, "habiéndole inoculado y no le prendió"79.

\footnotetext{
71 AASF, Expediente matrimonial de Catalina y Antonio Andino. 20 de abril de 1759. Información Matrimonial, 1756-1761, Expte. $n^{\circ} 86$.

72 AASF, Acta de matrimonio de Catalina y Antonio Andino. 29 de abril de 1759. Libro Bautismos, Confirmaciones, Matrimonios y Defunciones, 1752-1764, F. 32.

73 Una de las niñas que falleció había nacido el 14 de septiembre de 1790 y se llamó María de la Cruz, murió al año siguiente de viruelas.

74 AASF, Acta de defunción de Dominga Andino. 28 de diciembre de 1830. Libro de Defunciones, 1828-1842, F. 90.

75 AGPSF, CDA, Leg. 62, Carp 1, F. 6.

76 DEEC, EP, T. 20, 1807, Fs. 313-316.

77 AASF, Acta de matrimonio de María del Rosario Andino y Domingo Ignacio Ledezma. 28 de enero de 1810. Libro de Matrimonios, 1805-1819, F. 128.

78 AASF, Acta de bautismo de María Andrea Andino. 8 de febrero de 1811. Libro de Bautismos, 18091811 , Fs. $114 \mathrm{v}-115$.

${ }^{79}$ AGPSF, CDA, Leg. 62, Carp. 1, F. 6v.
} 


\section{Gonzalo Cáceres}

Finalmente, Dominguita, la última de los hijos de Dominga y Canciano, se casó con el pardo libre Francisco Orosco, un sastre oriundo de Tucumán. Ambos aparecen censados en la casa de Manuel Ignacio en 1816-17. El 21 de agosto de 1813 bautizaron a Juana Francisca ${ }^{80}$ que sobrevivió a la viruela y también fue registrada en el censo como esclava en lugar de liberta. En el registro bautismal de sus hermanos, Simón, nacido en 181781, y Francisca Antonia, nacida en 182082, sí se colocará en el margen su condición de libertos. Francisca Antonia morirá a los pocos meses de haber nacido.

Rita, la segunda hija de Catalina y Antonio, nació en 1769. Se mantuvo soltera y tuvo dos hijas naturales, Bernardina y Juliana. Juliana murió de viruelas en 1802, y Bernardina junto con su madre, fueron dadas en dote a Delfina, otra hija de Manuel Ignacio cuando se casó. Ambas fueron a vivir a Montevideo donde estaba radicada su nueva ama. Este último aspecto explicaría por qué ninguna de ellas fue censada en la casa de Andino en 1816-17. Sabemos por el manuscrito que Bernardina tuvo una hija -aunque no se menciona su nombre- y que ambas junto a Rita fueron liberadas por su ama el 24 de junio de 1820, cuando "dicha... de Montevideo se fue a España"83. ¿Por qué fueron liberadas? ¿Su ama no las quiso o no las pudo llevar en su viaje? ¿Se resistieron ellas a emprender ese viaje y negociaron con su ama su libertad? No lo podemos saber, tampoco qué fue de sus vidas luego de ser manumitidas.

El último de los hijos de Catalina y Antonio, también nombrado como su padre, Antonio, nació en 1771 y la única información que tenemos de él es que se casó con una mujer libre, de nombre Francisca. No lo hemos encontrado en el censo de 181617. Posiblemente, como en otros casos, Antonio haya pasado a manos de alguno de los hijos de Manuel Ignacio, o haya estado cumpliendo labores en las estancias o chacras de esta familia al momento del censo.

\section{La familia de Teresa e Hipólito Cabrera}

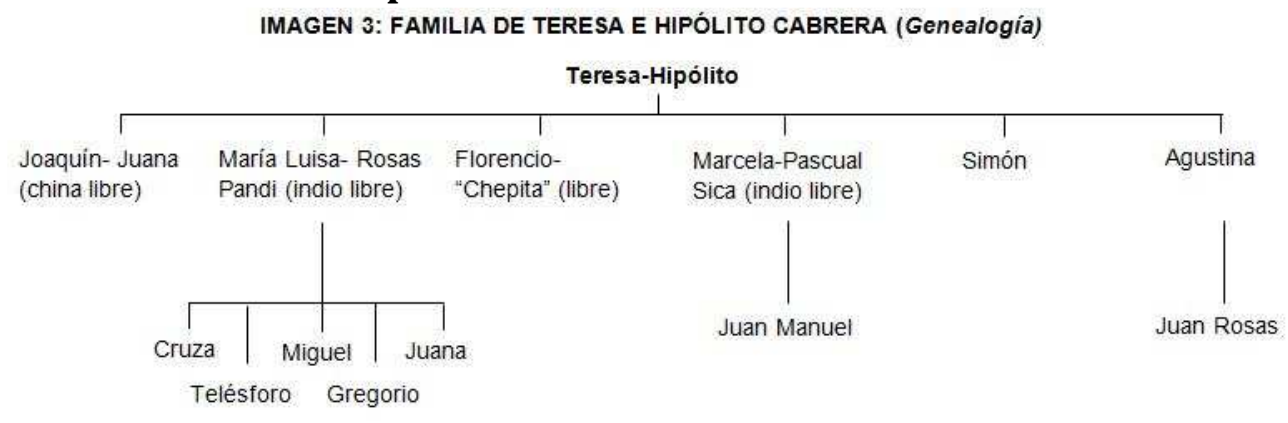

Fuente: CDA. Legajo 62, carpeta 1, f. 1-9, AGPSF; Informaciones Matrimoniales, Actas de Bautismo, Matrimonios y Defunciones, AASF.

\footnotetext{
${ }^{80}$ AASF, Acta de bautismo de Juana Francisca Andino. 21 de agosto de 1813. Libro de Bautismos, $1811-1814$, Fs. 245 y v. El acta versa "hija de esclava, gratis".

81 AASF, Acta de bautismo de Simón Andino. 28 de octubre de 1817. Libro de Bautismos, 1814-1819, F. 229v.

${ }^{82}$ AASF, Acta de bautismo de Francisca Antonia Andino. 2 de octubre de 1820. Libro de Bautismos, 1819-1826, F.59.

${ }^{83}$ AGPSF, CDA, Leg. 62, Carp. 1, F. 6.
} 


\section{Trayectorias familiares y experiencias individuales: el caso de los esclavizados de los Diez de Andino en Santa Fe (1763-1822)}

Como ya hemos señalado, la familia de Teresa e Hipólito perteneció a la Compañía de Jesús y fue adquirida por Manuel Ignacio en pública almoneda luego de la expulsión de esta orden. Según el manuscrito, Teresa e Hipólito fueron comprados junto a cuatro de sus hijos: Joaquín, María Luisa, Marcela y Florencio "de pechos"84. En los protocolos notariales hemos encontrado las escrituras de venta de Luisa y Marcela, que las pagó 125 y 105 pesos respectivamente ${ }^{85}$, no así las correspondientes a Hipólito, Teresa, Joaquín y Florencio. El relevamiento de esa documentación nos ha permitido identificar la escritura de venta de otra de sus hijas, Florentina, la cual fue adquirida por Don Juan de Santa Cruz ${ }^{86}$. Al tratarse de un remate público, las familias esclavas estaban sujetas a la posibilidad de la separación de sus integrantes, que fue lo que finalmente ocurrió. Hipólito y Teresa tuvieron dos hijos más que nacieron ya en propiedad de Andino, Simón y Agustina. De los tres hijos varones no tenemos mayor información que la consignada en el manuscrito. Según se indica allí, Joaquín se casó con Juana, china libre, y "tuvieron algunos hijos libres" que no pudimos identificar. De Florencio sabemos que se casó con una mujer libre, una tal "Chepita de las señoras Arismendi", y que aprendió el oficio de zapatero. Finalmente, de Simón sólo conocemos el año de su nacimiento, 1776.

De las tres hijas mujeres hallamos algunos datos más. María Luisa se casó con un indio, Rosas Pandi. Esta familia, según el manuscrito, cumplía labores en la estancia de San Miguel. Tuvieron cinco hijos: Cruza, Telésforo, Miguel, Gregorio y Juana. Según los registros parroquiales, tres de ellos (Telésforo de 7 años, Gregorio de 5 y Juana de 1) fueron bautizados el mismo día en la Capilla del Rosario ${ }^{87}$. Esta práctica para la época no era extraña, dado que como han señalado Barriera \& Tarragó (2006c: 161), "hasta bien entrado el siglo XX, los habitantes de las zonas rurales muchas veces registraban los nacimientos de varios niños a la vez". A Cruza, señala Manuel Ignacio en el documento, "la vendí a Don Santiago Domínguez en 300 pesos año de 1800 " 88 , mientras que Miguel fue otro de los esclavos que recurrió a la fuga, aunque no con mucho éxito: "habiéndose huido tres veces pareció la última en Chascomun (sic)", lo vendió Rafael, hijo de Manuel Ignacio, en 250 pesos, en septiembre de $1816^{89}$.

Marcela también se casó con un indio, Pascual Sica, natural del Paraguay, que huyó y la dejó con sus hijos. No hemos encontrado información sobre ellos, y en el manuscrito sólo se menciona a uno, Juan Manuel, que nació en 1795 y que Andino lo

\footnotetext{
${ }^{84}$ AGPSF, CDA, Leg. 62, Carp. 1, Fs. 8 y v.

85 DEEC, EP, T. 17, 1775, F. 607; DEEC, EP, T. 17, 1775, F. 611.

86 DEEC, EP, T. 17, 1775, F. 610.

87 AASF, Acta de bautismo de Telésforo Pandi. 17 de abril de 1800. Libro de Bautismos, 1795-1805, F. 91; AASF, Acta de bautismo de Juana Andino. 17 de abril de 1800. Libro de Bautismos, 1795-1805, F. 91v; AASF, Acta de bautismo de Gregorio Pandi. 17 de abril de 1800. Libro de Bautismos, 17951805, F. 91v.

${ }^{88}$ AGPSF, CDA, Leg. 62, Carp. 1, F. 8v.

${ }^{89}$ AGPSF, CDA, Leg. 62, Carp. 1, Fs. 8 y v.
} 


\section{Gonzalo Cáceres}

dio "al padre comendador Doctor fray Hilario Torres en 100 pesos y 150 misas el 14 de diciembre de 1812"90. Marcela murió "de esquilencia (sic) y embarazada en mayo de $1801 " 91$.

Por último, de Agustina sabemos que nació en 1778 y que tuvo un hijo nombrado Juan Rosas ${ }^{92}$, a quienes Andino vendió en 1796 a Don Tomás Priavia en 300 pesos $^{93}$.

\section{Conclusiones}

La esclavitud para las generaciones de esclavizados que pertenecieron a la familia Diez de Andino parece haber sido una condición de difícil superación. Posiblemente más a consecuencia de la poca voluntad de los amos a habilitar canales de movilidad social para sus esclavos que producto de la pasividad de éstos para crearse un mejor destino.

Las historias familiares como los derroteros individuales de estas personas revelan aspectos sensibles propios de su situación de cautiverio pero a la vez dan cuenta de su capacidad para sobreponerse a una realidad impuesta. Tanto unos como otros fueron piezas claves en el entramado productivo y en el mantenimiento de las diversas propiedades de sus amos. Algunos estuvieron confinados más a unas que a otras, mientras que otros articularon estacionalmente su estadía en las casas, chacras y estancias dependiendo de las labores a realizar.

Las posibilidades de ascenso social estuvieron muy limitadas para la mayoría de estas personas. Hemos visto cómo familias completas estuvieron sujetas a servidumbre generación tras generación, soportando la separación de sus integrantes y la desarticulación de sus vínculos familiares según los designios de sus amos, que los vendieron a veces en regiones alejadas, los cedieron a sus parientes o los intercambiaron por otros a voluntad. En este punto es preciso remarcar que hacen falta más estudios que nos permitan conocer qué fue de las vidas de los esclavizados que quedaron fuera de la órbita de control de esta familia, para reconocer si estamos en presencia o no de un caso singular.

Respecto de las uniones matrimoniales, hemos observado que un buen número de ellas se dieron entre miembros de las familias afrodescendientes con individuos de las parcialidades indígenas, aspecto que revela no sólo el proceso de mestizaje que se operaba entre estos actores sociales, sino que también nos permite tener un panorama de la cotidianidad del mundo colonial, en la que estos grupos compartían espacios laborales y hasta habitaban las mismas unidades domésticas junto al sector dominante español al cual estaban sujetos por distintas relaciones de dependencia, como esclavos, conchabados, etc.

En particular, las uniones matrimoniales que se concretaron entre esclavos con personas libres casi no modificaron la situación del componente esclavo. Si en el

\footnotetext{
${ }^{90}$ AGPSF, CDA, Leg. 62, Carp. 1, F. 8v.

91 AGPSF, CDA, Leg. 62, Carp. 1, F. 8v.

92 AGPSF, CDA, Leg. 62, Carp. 1, F. 8v.

93 DEEC, EP, T. 19, 1796, Fs. 579-581.
} 


\section{Trayectorias familiares y experiencias individuales: el caso de los esclavizados de los Diez de Andino en Santa Fe (1763-1822)}

caso de los varones al menos se garantizó la libertad de su descendencia, no fue así con las mujeres. Sus hijos siguieron naciendo esclavos y no hemos encontrado casos de movilidad social que den cuenta del aprovechamiento de la "pata libre" de la familia, para lograr una manumisión por ejemplo. Sí, en cambio, advertimos una estrategia de aprovechamiento de esa mano de obra por parte de los dueños que, a través de esas uniones, retenían al componente libre para su servicio.

El potencial reproductivo de las mujeres esclavas fue muy aprovechado por los amos. Vimos que la principal forma de abastecimiento de cautivos a la que recurrió Manuel Ignacio fue por la vía de los nacimientos de hijos de sus esclavas. Aunque se produjeron algunas compras e ingresaron al patrimonio familiar nuevos esclavos por la dote de su esposa o por el cobro de deudas, la gran mayoría de los esclavizados que estuvieron bajo su dominio nacieron de las esclavas que fueron heredadas de su padre y de las hijas, nietas y bisnietas de esas esclavas. Muchas procrearon en el marco de una relación estable, otras no. El número considerable de casos de esclavizadas con hijos naturales que hemos reseñado, nos hablan de la precariedad de la vida de estas mujeres.

Por otra parte, el registro en el manuscrito de las fugas de los esclavizados y la redacción de poderes para su captura refleja las estrategias de resistencia de éstos a la vez que evidencia la dificultad de fijación de la mano de obra cautiva por parte de los amos. Hemos visto que las huidas se produjeron centralmente en las estancias, es decir, en espacios alejados y menos vigilados, al amparo de una campaña abierta que facilitaba el escondite y la dispersión, y que éstas fueron protagonizadas por esclavos varones. Es decir, las actividades y los espacios donde tenían lugar esas actividades permitieron a los varones desarrollar esta estrategia de resistencia, estrategia que prácticamente estuvo vedada para las mujeres que se vieron confinadas casi exclusivamente al hogar donde la relación con sus amos era más estrecha y por tanto el control más estricto. Las fugas prosperaron gracias a las redes de solidaridad tejidas entre los mismos esclavizados. Ciertamente estas acciones se concretaron con algo más que la simple voluntad de huir. El riesgo de la captura y los castigos estuvieron siempre latentes por lo que era necesario contar con cierto apoyo logístico, esto es, alguien que facilitara cobijo y alimentación. La estrategia de usar nombres falsos o hacerse pasar por libres no siempre funcionó ante la mirada atenta de captores y vecinos muy instruidos sobre las "señas" de los esclavos fugitivos. Ello hizo que en algunas ocasiones las fugas fracasaran. No obstante, como hemos mostrado, muchas tuvieron un notable éxito y los amos no volvieron a tener más noticias de sus esclavos. Este aspecto, unido a las escasas manumisiones que registramos en nuestro análisis nos lleva a discutir el supuesto carácter benigno de la esclavitud sostenido por una parte de la historiografía en Argentina, y en Santa Fe en particular.

Por último, vimos que las afecciones, dolencias y padecimientos fueron recurrentes en las historias de estos esclavizados. En tanto grupos vulnerados soportaron los traumas del traslado forzoso, fueron presa de enfermedades infecciosas y se vieron obligados a soportar rutinas de trabajo agobiante. A pesar de la inversión en 


\section{Gonzalo Cáceres}

médicos y vacunas por parte de Andino, en procura de preservar ese patrimonio, un número importante de cautivos perdió la vida.

La historia de los esclavos de la familia Andino ciertamente no es la historia de todos los cautivos santafesinos, aunque es posible que algunas de las experiencias que aquí hemos reseñado guarden alguna similitud con las vivencias cotidianas de muchos de los esclavizados que habitaron la ciudad durante la etapa colonial e independiente.

\section{Bibliografía}

Aguirre, C. (1991). Agentes de su propia emancipación: manumisiones de esclavos en Lima, 1821-1854. Apuntes (29).

Albores, O., Mayo, C. \& Swenney, J. (1994). Esclavos y conchabados en la estancia Santa Catalina, Córdoba (1764-1771). En C Mayo (comp.); La historia Agraria del Interior. Haciendas jesuíticas de Córdoba y el Noroeste. Buenos Aires: Centro Editor de América Latina.

Andrews, G. R. (1989). Los afroargentinos de Buenos Aires. Buenos Aires: Ediciones de la Flor.

Areces, N. (2004). La compañía de Jesús en Santa Fe, 1610-1767. Las tramas del poder. En T. Suárez \& Areces, N. (comps.); Estudios históricos regionales en el espacio rioplatense: de la colonia a mediados del siglo XIX. Santa Fe: Ediciones UNL.

Baravalle, M. R. (2001). Introducción a un tema sin historio. Negros esclavos en Santa Fe, siglo XVII. Claroscuro (1).

Baravalle, M. R. (2006). Los esclavos y la esclavitud. En D. Barriera (dir.); Nueva historia de Santa Fe, Tomo III, Economía y sociedad, siglo XVI a XVIII. Rosario: Prohistoria - La Capital.

Baravalle, M. R. (2018). Esclavos, jesuitas y vecinos en la Gobernación del Río de la Plata. Rosario: Prohistoria.

Barriera, D. \& Tarragó, G. (2003). Elogio de la incertidumbre. La construcción de la confianza: entre la previsión y el desamparo. (Santa Fe, Gobernación del Río de la Plata, siglo XVIII). Revista de historia de la universidad de Costa Rica, (48). 


\section{Trayectorias familiares y experiencias individuales: el caso de los esclavizados de los Diez de Andino en Santa Fe (1763-1822)}

Barriera, D. \& Tarragó, G. (2005). De la confianza a la composición. Cultura del riesgo, de la previsión y de la resolución de conflictos entre mercaderes del siglo XVIII. En B. Vázquez, \& G. Dalla Corte (eds.); Empresarios y empresas en América Latina Siglos XVIII-XIX, Maracaibo: Ediluz.

Barriera, D. \& Tarragó, G. (2006a). La traición de Manuel. Negocios, familias y justicia, del Paraguay a Potosí. En D. Barriera (dir.); Nueva historia de Santa Fe, Tomo III, Economía y sociedad, siglo XVI a XVIII. Rosario: Prohistoria - La Capital.

Barriera, D. \& Tarragó, G. (2006b). Adiós a la monarquía. De los años revolucionarios a la crisis de 1820. En D. Barriera (dir.); Nueva historia de Santa Fe, Tomo IV, Rosario, Prohistoria - La Capital.

Barriera, D. \& Tarragó, G. (2006c). Transformaciones en un espacio de frontera. La población, los recursos y las rutas". En D. Barriera (dir.) Nueva historia de Santa Fe, Tomo III, Economía y sociedad, siglo XVI a XVIII. Rosario: Prohistoria - La Capital.

Bernand, C. (2001). Negros esclavos y libres en las ciudades hispanoamericanas. Madrid: Fundación Histórica Tavera.

Borucki, A. (2017). De compañeros de barco a camaradas de armas. Identidades negras en el Río de la Plata, 1760-1860. Buenos Aires: Prometeo.

Cáceres, G. (2019a). Mercado esclavista, orígenes y circulaciones regionales e interjurisdiccionales. Santa Fe, 1750-1810. Claves. Revista de Historia (5: 9).

Cáceres, G. (2019b). Esclavos en Santa Fe colonial: mercado, estrategias de libertad y matrimonios, 1750-1810. Ponencia presentada en las XVII jornadas interescuelas de historia, Catamarca.

Calvo, L. M. (1993). La compañía de Jesús en Santa Fe. La ocupación del espacio urbano y rural durante el dominio hispánico. Santa Fe: ediciones Culturales Santafesinas.

Candioti, M. (2010). Altaneros y libertinos. Transformaciones de la condición jurídica de los afroporteños en la Buenos Aires revolucionaria (1810-1820). Desarrollo Económico (198: 50).

Candioti, M. (2016a). Hacia una historia de la esclavitud y la abolición en la ciudad de Santa Fe, 1810-1853. En A.Frigerio, F. Guzmán \& L. Geler (eds.); Cartografías afrolatinoamericanas. Perspectivas situadas desde la Argentina. Buenos Aires: Biblos.

Candioti, M. (2016b). Abolición gradual y libertades vigiladas en el Río de la Plata. La política de control de libertos de 1813. Corpus (1: 6) [En línea] DOI: https://doi.org/10.4000/corpusarchivos.1567 


\section{Gonzalo Cáceres}

- (2018). Manumisiones negociadas y libertades frágiles en el Río de la Plata. Santa Fe, 1810-1853. En J. Freire \& M. V. Secreto (orgs.); Formas de liberdade. Gratidäo, condicionalidade e incertezas no mundo escravista nas Américas. México, Cuba, Porto Rico, Santo Domingo, Caribe Francës, Brasil e Argentina. Río de Janeiro: Mauad.

Candioti, M. et al. (2019). Esclavos, libres y libertos en la ciudad de Santa Fe a inicios del siglo XIX. Un análisis demográfico y social a partir del padrón de población de 1816-1817. En M. Ghirardi (ed.); Esclavos. Historia de una subjetividad negada. Córdoba: Báez.

Caula, E. \& Tarragó, G. (2003). Cuando el mañana sólo era desamparo: comerciantes rioplatenses en tiempos de guerra. 1806-1820, Prohistoria (7).

Cervera, M. (1907). Historia de la ciudad y provincia de Santa Fe. Santa Fe: Ediciones UNL.

Covarrubias, S. (1611). Tesoro de la lengua castellana o española. Madrid: Luís Sánchez. Original recuperado

en https://books.google.es/books?id=K10MJdL7pGIC\&printsec=frontcover\&dq=tesor o+de+la+lengua+castellana+o+espa\%C3\%B1ola\&hl=es\&ei=oJZfTaa2MoS08QOIj9h

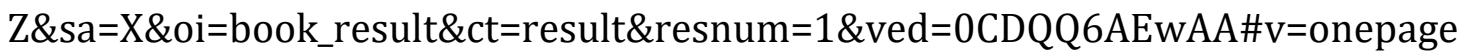
$\& \mathrm{q}=$ tesoro $\% 20 \mathrm{de} \% 20 \mathrm{la} \% 20$ lengua $\% 20$ castellana $\% 200 \% 20$ espa $\% \mathrm{C} 3 \% \mathrm{~B} 1 \mathrm{ola} \& \mathrm{f}=\mathrm{f}$ alse[Consultado el 28/5/20].

Diez de Andino, Manuel Ignacio (2008). Diario de Don Manuel Ignacio Diez de Andino: crónica santafesina, 1815-1822. Santa Fe: Ediciones UNL.

Dimunzio, K. \& García, C. (2006). Esclavos cimarrones. La fuga: una estrategia de resistencia esclava. Contra Relatos desde el Sur. Apuntes sobre África y Medio Oriente (3).

Frías, S. \& Monserrat, M. I. (2017). Pestes y muerte en el Río de la Plata y Tucumán (1700-1750). Temas de historia argentina y americana (1: 25).

Goldberg, M. \& Mallo, S. (2005a). Trabajo y vida cotidiana de los africanos en Buenos Aires (1750-1850). En M. Goldberg (dir.); Vida cotidiana de los negros en Hispano América. Madrid: Ignacio Larramendi-MAPFRE Tavera.

Goldberg, M. \& Mallo, S. (2005b). Vida y muerte cotidianas de los negros en el Río de la Plata". En M. Goldberg (dir.); Vida cotidiana de los negros en Hispanoamérica. Madrid, Ignacio Larramendi-MAPFRE Tavera.

Guzmán, F. (1997). Familias de los esclavos en La Rioja tardocolonial (1760-1810). Andes. Antropología e Historia (8). 


\section{Trayectorias familiares y experiencias individuales: el caso de los esclavizados de los Diez de Andino en Santa Fe (1763-1822)}

Guzmán, F. (2013). Afroargentinos, guerra y política, durante las primeras décadas del siglo XIX. Una aproximación hacia una historia social de la revolución. Estudios Históricos (11).

Johnson, L. (1976). La manumisión de esclavos en Buenos Aires durante el Virreinato. Desarrollo Económico (63: 16).

Johnson, L. (1978). La manumisión en el Buenos Aires colonial: un análisis ampliado. Desarrollo Económico (68: 17).

Johnson, L. (2013). Los talleres de la revolución. La Buenos Aires plebeya y el mundo del Atlántico, 1776-1810. Buenos Aires: Prometeo.

Klein, H. (2002). O comercio atlántico de escravos. Quatro séculos de comércio esclavagista. Lisboa: Editora Replicação Lda.

Lucena Salmoral, M. (1999). El derecho de coartación del esclavo en la América española", Revista de Indias. (LIX: 216).

Mallo, S. \& Telesca, I. (2010). Negros de la patria. Los afrodescendientes en las luchas por la independencia en el antiguo Virreinato del Río de la Plata. Buenos Aires: SB.

Mallo, S. (2005). Experiencias de vida, formas de trabajo y búsqueda de libertad. En Memoria del simposio. La Ruta del Esclavo en el Río de la Plata: su historia y sus consecuencias. Montevideo, UNESCO.

Mayo, C. (1997). Patricio de Belén: nada menos que un capataz. The Hispanic American Historical Review (4: 77).

Moriconi, M. (2011). El curato de naturales en Santa Fe. Río de la Plata. Siglos XVIIXVIII. Hispania Sacra (LXIII: 218).

Moriconi, M. (2018). Voz y quebranto. Teodora, esclavizada y fugitiva en la cultura jurisdiccional del Río de la Plata (1758). Historia y Justicia (11).

Ogass Bilbao, C. (2009). Por mi precio o mi buen comportamiento: oportunidades y estrategias de manumisión de los esclavos negros y mulatos en Santiago de Chile, 1698-1750. Historia (42).

Pistone, C. (1996). La esclavatura negra en Santa Fe. Santa Fe: Junta Provincial de Estudios Históricos.

Rebagliati, L. (2014a). Negros y mulatos pobres en Buenos Aires (1786-1821). Quinto Sol (18: 1). 


\section{Gonzalo Cáceres}

Rebagliati, L. (2014b). ¿Una esclavitud benigna? La historiografía sobre la naturaleza de la esclavitud rioplatense. Andes. Antropología e historia (2: 25).

Rosal, M. A. (2009). Africanos y Afrodescendientes en el Río de la Plata. Siglos XVIIIXIX. Buenos Aires: Dunken.

Saguier, E. (1989). La naturaleza estipendiaria de la esclavitud urbana colonial. El caso de Buenos Aires en el siglo XVIII. Revista Paraguaya de Sociología (74).

Saguier, E. (1995). La crisis social, la fuga esclava como resistencia rutinaria y cotidiana. Revista de Humanidades y Ciencias Sociales (1: 2).

Silvestri, N. (2017). Los matrimonios de esclavos en la Santa Fe colonial hacia mediados del XVIII. Estudios del ISHiR (19).

Silvestri, N. (2019). Experiencias de la esclavitud en una modernidad colonial: las mujeres esclavizadas frente al matrimonio en Santa Fe del Río de la Plata en el siglo XVIII. En M. Moriconi (dir.); Sabedoras y desvergonzadas. Ensayos de investigación para una enseñanza generizada de la historia medieval y moderna. Rosario: hya ediciones.

Suárez, T. (1993). Sexualidad y sociedad en la colonia marginal: Santa Fe, 1680-1780 (Tesis de doctorado inédita). Universidad Nacional de La Plata. Facultad de Humanidades y Ciencias de la Educación, La Plata.

Tarragó, G. (1993). Los Diez de Andino: un linaje colonial santafesino (1660-1822). Cuadernos de Historia Regional (16).

Tarragó, G. (1994). Parentesco y comercio en Santa Fe en el siglo XVIII. Anuario de la escuela de historia (16).

Tarragó, G. (1996). Santa Fe en el período tardo-colonial: producción ganadera, estancias y regiones. Anuario de la Escuela de Historia (17).

Tarragó, G. (2004). Fundar el linaje, asegurar la descendencia, construir la casa. La historia de una familia en indias: los Diez de Andino entre Asunción del Paraguay y Santa Fe de la Vera Cruz (1660-1822). En J. M. Imízcoz (ed.); Casa, familia y sociedad (País Vasco, España y América, siglos XV-XIX)", Bilbao: Universidad del País Vasco/ Euskal Herriko Unibertsitatea.

Tarragó, G. (2010). Redes mercantiles y prácticas comerciales: mercaderes y comerciantes rioplatenses en la primera mitad del siglo XVIII. En G. Sabatini (coord.); Comprendere le monarchie iberiche. Risorse materiali e reppresentazioni del potere. Roma: Viella. 
Trayectorias familiares y experiencias individuales: el caso de los esclavizados de los Diez de Andino en Santa Fe (1763-1822)

Troisi Melean, J. (2012). El oro de los jesuitas. La compañía de Jesús y sus esclavos en la Argentina colonial. Saarbrücken: Editorial Académica Española.

Valenzuela, F. (2017). De esclavizados a libres y libertos. Formas de alcanzar la libertad en Corrientes (1800-1850). Trashumante (10).

Zacca, I. (1997). Matrimonio y mestizaje entre los indios, negros, mestizos y afromestizos en la ciudad de Salta (1766-1800). Andes. Antropología e Historia (8).

Zapata Gollán, A. (1987). Los negros. América (6).

Recibido: 02/07/2021

Evaluado: 03/08/2021

Versión Final: 01/08/2021 